\title{
Dexrazoxane Hydrochloride
}

\author{
National Cancer Institute
}

\section{Source}

National Cancer Institute. Dexrazoxane Hydrochloride. NCI Thesaurus. Code C66945.

The hydrochloride salt of a bisdioxopiperazine with iron-chelating, chemoprotective, cardioprotective, and antineoplastic activities. After hydrolysis to an active form that is similar to ethylenediaminetetraacetic acid (EDTA), dexrazoxane chelates iron, limiting the formation of free radical-generating anthracycline-iron complexes, which may minimize anthracycline-iron complex-mediated oxidative damage to cardiac and soft tissues. This agent also inhibits the catalytic activity of topoisomerase II, which may result in tumor cell growth inhibition. 